\title{
Support for New Faculty Members: What do They Perceive They Need?
}

\author{
Jennifer Boman, Michelle Yeo, \& Theresa Matus \\ Mount Royal University
}

In this article we report the outcomes of a needs assessment administered to new faculty members who were hired within the last four years at Mount Royal University. Our purpose in conducting this needs assessment was to gather information to guide the redevelopment of the institution's support program for new faculty in light of a changing institutional context (i.e., the transition from a college to a university). Faculty members were asked what kinds of support and resources they perceived themselves as needing during the first year of their full-time appointment and what gaps were present in their professional development. We review the key themes in faculty members' self-identified needs and summarize the principles behind a new faculty development program that was informed by the results of this research.

\section{Introduction}

A lthough beginning a full-time academic career is an exciting prospect for many new faculty members, this sense of anticipation often transitions to considerable anxiety once the job begins. The transition to a faculty career is a demanding one. New faculty members must learn and navigate the expectations of their new role while simultaneously executing and balancing the various responsibilities associated with being a faculty member. The literature on new faculty over the last two decades consistently indicates that adaptation to this role is often characterized by significant concerns (Boice, 1991; Eddy \& Gaston-Gayles, 2008; Menges, 1999; Olsen \& Sorcinelli, 1992). For example, new faculty report stressors such as unclear expectations, challenges in balancing professional and personal responsibilities, and a significant shortage of time to accomplish everything (Austin, 2003; Boice, 1991, 2000; Menges, 1999; Rice, Sorcinelli, \& Austin, 2000; Sorcinelli, 1994, 2000, 2002). In particular, many new faculty members suggest that they spend the majority of their time engaged in teaching preparation and yet still do not feel prepared for their classes (Murray, 2008; Solem $\&$ Foote, 2006). In addition to these stressors, some new faculty perceive a lack of support from colleagues, which can contribute to a sense of isolation in their new role (Sorcinelli, 1992). Taken together, these findings highlight the need for support for new faculty.

The literature on new faculty describes several different approaches to new faculty support, ranging from orientations to intensive courses on teaching development to formal and informal mentoring programs 
(Cawyer, Simonds \& Davis, 2010; Fink, 1992; Postareff, Lindblom-Ylänne, \& Nevgi, 2007; Solem \& Foote, 2006; Sorcinelli, 1994; Trigwell, Rodriguez, \& Han, 2011). These initiatives are designed to address concerns shared by new faculty, such as the need for relationship building among colleagues and the need for teaching and research support. More recently, attention has also been given to the need to prepare future faculty before they take on faculty appointments (Eddy \& Gaston-Gayles, 2008; Murray, 2008; Solem \& Foote, 2006). Research on new hires suggests that, while graduate school may offer some initial socialization to a faculty career, there are inconsistencies in the types of preparation provided to graduate students (Austin, 2003; Eddy \& Gatson-Gayles, 2008). Given that new faculty members may be arriving at institutions with varying degrees of preparation and experience, their needs for professional development and support may differ according to their diverse experiences.

The purpose of our study was to identify the needs of new faculty at our institution and to use this information to guide the redevelopment of a support program for new faculty. Our institution, Mount Royal University, is a medium-sized undergraduate teaching institution with approximately 400 full-time faculty members and 14,000 students. It was previously Mount Royal College but was accepted into the Association of Universities and Colleges of Canada and designated a university in 2009. Our reason for conducting this study was prompted, in part, by a changing institutional context and the hiring of a large number of new faculty members within a span of five years. The existing new faculty support program was developed when the institution was a college; therefore, we wished to take stock of the professional development needs of current new faculty to bring the program up to date.

\section{Data Collected}

We conducted a needs assessment of faculty members who were hired into full-time positions at Mount Royal during the previous four years. This group contained faculty members in their first academic appointments (including new $\mathrm{PhDs}$ as well as those with professional/industry experience), those with experience at other institutions but new to Mount Royal, and those transitioning from part-time to full-time appointments. Eligible participants were emailed a link to an anonymous online survey in which we asked them to reflect back on what they needed as a new faculty member with respect to orientation; building relationships; support for teaching, research, and service; and information about the tenure and promotion process during their first year. We also asked participants what gaps remained in their professional development after their first year and what advice they had for the structure and content of a program for orienting new faculty. In total, 41 faculty members completed the needs assessment, which reflects approximately a $25 \%$ participation rate.

\section{Themes Arising From the Data}

\section{Importance of collegial relationships}

The value of forming relationships with others in the institution was a dominant theme throughout the survey. New faculty members appreciated the opportunity to connect with others who were new as well as to form relationships both within and outside of their departments. Participants mentioned several different purposes for these relationships. First, many participants acknowledged that there is much to be learned from talking to faculty members in other disciplines and that it is a good opportunity to share ideas. In particular, new faculty wanted to talk to cross-department colleagues about teaching and also wanted to form research networks with colleagues who had similar interests. Others suggested that getting to know individuals across the institution helped them to understand the culture and provided necessary social opportunities. Finally, many new faculty members mentioned the value of having supportive networks. While they noted that orientation activities provided initial opportunities for connecting with other faculty members, many expressed a desire for more formalized ongoing mentoring throughout the year. This need for mentorship was mentioned across all categories of the faculty role, including teaching, research, service (e.g., mentorship for those new to committees), and the tenure and promotion process.

\section{Individualized support}

A second theme throughout the survey was the need for individualized support. It was apparent in the survey responses that some new faculty members had a high 
need for intensive support throughout the first year, while others needed much less support. For example, some new faculty were already very experienced teachers and felt well equipped for their teaching responsibilities. Other new faculty members had never taught before and needed a great deal of support in all areas of teaching, from course design to presentation methods to assessment to classroom management. A similar picture emerged for research. Some new faculty came with well-developed research plans and simply needed resources like time and money to continue their research. In contrast, other faculty members reported that they needed help in developing research networks and identifying a program of research. Not surprisingly, the need for individualized programming also came across in responses to new faculty members' need for orientation. Some new faculty were not 'new' in that they had been at the institution for several years prior to starting their full-time position and did not need the same depth of orientation as someone brand new to the institution.

\section{Clarity of expectations}

Although new faculty members had diverse needs with respect to support for teaching and research, one common thread across the survey responses was a shared need among new faculty to better understand the expectations of their faculty role. The theme of understanding what is expected of faculty members at the institution was mentioned across the categories of teaching, research, service, and tenure and promotion. Part of the confusion about expectations related to understanding what the performance expectations were for tenure and promotion and the other aspect involved understanding the actual process of tenure and promotion. As one faculty member mentioned, "This has been an ongoing mystery." Some of the uncertainty identified by new faculty may relate to the fact that the institution was in the process of developing tenure and promotion criteria during the time that many new faculty members were hired. However, understanding expectations is identified as a key concern for many new hires in the literature on new faculty (Solem \& Foote, 2006; Murray, 2008).

\section{Principles for the Renewed Program}

In addition to better understanding the needs of new faculty members, we also felt the needs assessment was a valuable opportunity to have new faculty themselves contribute to the redevelopment of the new faculty support program. As such, we asked faculty members for their suggestions regarding what they would find helpful in a redesigned program. The following three principles emerged in the survey, via broader consultation, and were also supported by our review of the literature. We used these principles as the cornerstone for the program's redevelopment.

\section{Choice and responsiveness}

New faculty members identified the principle of choice as a key component of a new faculty support program. As one participant noted, "it would be useful to offer a variety of sessions and allow people to sign up for what they feel would be most beneficial." Indeed, when new faculty were asked what suggestions they had for content for a new program, the ideas were diverse and covered a wide range of topics. It is evident that new faculty members have different needs, and we agree that offering as much choice as possible would help individualize the program. The principle of choice also speaks to "just in time learning' in that participants would be better able to access content and information as they needed it. Finally, offering new faculty members choices about what and when to attend would help us be more responsive in terms of the level of support. Individuals who required more intensive support would be able to sign up for additional offerings within the program and participants would have the option of attending sessions that focused more on issues of relevance for those new to teaching.

\section{Opportunities for collegial relationships}

A second principle that was highlighted in the survey data was new faculty members' desire for a new program to preserve opportunities to build relationships with colleagues. Participants consistently listed the sense of community with other faculty members as a key component of a support program. As one participant commented, "orientation is incredibly useful for the connections you make." Other participants added that there is great value in opportunities throughout the year to reconnect with other new faculty members and to "talk/normalize experiences." Participants also felt that relationships with a mentor or more experienced 
colleague would be a particularly useful form of support during their first year.

\section{Current and collaborative professional practice}

New faculty members' desire for a program that is collaborative in nature was emphasized in the survey results. For example, participants wanted information about current best practices in teaching and assessment but they also wanted to take an active role in suggesting ways to use the information and adapt it to their context. As one participant suggested, there is no 'one-size-fits-all' approach to teaching and new faculty members themselves have expertise and experience to draw on and share with others in a collaborative fashion. New faculty members seemed to have a strong sense of identity as 'professionals' and wanted a program that acknowledged their expertise as well as their needs for growth.

\section{Reflections and Next Steps}

Hearing from new faculty members in their own words about their needs helped us to formulate principles for a new faculty development program. Their responses were consistent with established themes in the literature and confirmed our intuitions about needed changes. A key change we incorporated into our new program included a move to allow more choice, creating a wider range of optional sessions for new faculty. We now hold a brief orientation and delay some orientation material until later (allowing for more initial time in departments). We are creating a listserv for new faculty to keep them connected with each other and to serve as a mechanism to get ongoing feedback on ideas for professional development sessions. In addition, we are exploring the possibility of an institutional mentoring program for new faculty that crosses departmental boundaries. Finally, we intend to create an optional professional learning community for new faculty, which would provide an ongoing and structured place to explore the theory and practice of teaching along with other issues for new faculty who would benefit from this level of support. Through ongoing review processes and consultation, we hope to continue to adapt the program, not only to individual participant needs, but also to institutional context, as well as broader changes within the postsecondary environment.

\section{References}

Austin, A.E. (2003). Creating a bridge to the future: Preparing new faculty to face changing expectations in a shifting context. The Review of Higher Education, 26(2), 119-144.

Boice, R. (1991). New faculty as teachers. Journal of Higher Education, 62(2), 150-173.

Boice, R. (2000). Advice for new faculty members. Boston, MA: Allyn \& Bacon.

Cawyer, C.S., Simonds, C., \& Davis, S. (2002). Mentoring to facilitate socialization: The case of the new faculty member. International Journal of Qualitative Studies in Education, 15(2), 225-242.

Eddy, P.L. \& Gaston-Gayles, J.L. (2008). New faculty on the block: Issues of stress and support. Journal of Human Behavior in the Social Environment, 17(12), 89-106.

Fink, L.D. (1992). Orientation programs for new faculty. New Directions for Teaching and Learning, 50 (Summer), 39-49.

Menges, R.J. (1999). Dilemmas of newly hired faculty. In R. J. Menges \& Associates (Eds.), Faculty in new jobs: A guide to settling in, becoming established, and building institutional support (pp. 19-38). San Francisco: Jossey-Bass.

Murray, J.P. (2008). New faculty members' perceptions of the academic work life. Journal of Human Behavior in the Social Environment, 17(1-2), 107-128.

Olsen, D. \& Sorcinelli, M. D. (1992). The pretenure years: A longitudinal perspective. New Directions for Teaching and Learning, 50 (Summer), 15-25.

Postareff, L., Lindblom-Ylänne, S., \& Nevgi, A. (2007). A follow-up study of the effect of pedagogical training on teaching in higher education. Higher Education, 56, 29-43.

Rice, R.E., Sorcinelli, M.D., \& Austin, A.E. (2000). 
Heeding new voices: Academic careers for a new generation. Inquiry \#7. Working Paper Series. New Pathways: Faculty Careers and Employment for the $21^{\text {st }}$ Century. Washington, D.C.: American Association for Higher Education.

Solem, M.N. \& Foote, K.E. (2006). Concerns, attitudes, and abilities of early-career geography Faculty. Journal of Geography in Higher Education, 30(2), 199-234.

Sorcinelli, M.D. (1992). New and junior faculty stress: Research and responses. New Directions for Teaching and Learning, 50 (Summer), 27-37.

Sorcinelli, M.D. (1994). Effective approaches to new faculty development. Journal of Counseling \& Development, 72(5), 474-479.

Sorcinelli, M.D. (2000). Principles of good practice: Supporting early-career faculty. Guidance for deans, department chairs, and other academic leaders. Washington, DC: AAHE.

Sorcinelli, M.D. (2002). New conceptions of scholarship for a new generation of faculty members. New Directions for Teaching and Learning, 90, 41-48.

Trigwell, K., Rodriguez, K.C., and Han, F. (2011). Assessing the impact of a university teaching development programme. Assessment \& Evaluation in Higher Education, 37(4), 499-511.

\section{Biographies}

Jennifer Boman is a Faculty Development Consultant and Assistant Professor in the Academic Development Centre at Mount Royal University. Her research interests include new faculty and graduate teaching assistant development, program design and evaluation, and the impact of teaching behaviours on student learning and motivation.

Michelle Yeo is a Faculty Development Consultant and Associate Professor in the Academic Development Centre at Mount Royal University. Her research interests include new faculty induction and experience, new literacies, and student experiences at post-secondary institutions.

Theresa Matus is the Director of the Academic Development Centre at Mount Royal University. 